\title{
Electrospun Nanofibrous Polyacrylonitrile/calixarene Mats: an Excellent Adsorbent for the Removal of Chromate Ions from Aqueous Solutions
}

\author{
Mevlut Bayrakci, ${ }^{1, *}$ Fatih Ozcan, ${ }^{2}$ Bahar Yilmaz $^{1}$ and Seref Ertul ${ }^{2}$ \\ ${ }^{1}$ Department of Bioengineering, Faculty of Engineering, Karamanoglu Mehmetbey University, Karaman, Turkey \\ ${ }^{2}$ Department of Chemistry, Faculty of Science, Selcuk University, Konya, Turkey \\ * Corresponding author: E-mail: mevlutbayrakci@ gmail.com \\ Tel.: +903882252106 fax: +903882250180;
}

Received: 18-05-2017

\begin{abstract}
Herein, calixarene molecules containing piperidine units at lower rim or upper rim of calix skeleton was turned into a water resistant composite nanofiber adsorbent using polyacrylonitrile (PAN) polymeric support via electrospinning process. The PAN based calixarene nanofibrous adsorbents showed an excellent adsorption capacity toward the toxic chromate anions in aqueous solution. Furthermore, this new nanofiber mats would be promising filter materials for drinking water purification.
\end{abstract}

Keywords: Calixarene, Nanofiber, Membrane, Chromate, Electrospining

\section{Introduction}

Chromium is a naturally occurring element and found in rocks, animals, plants, soil, and in volcanic dust and gases. ${ }^{1}$ Chromium can exist in four different oxidation states such as metallic chromium $\mathrm{Cr}$, chromous $\mathrm{Cr}^{2+}$, chromic $\mathrm{Cr}^{3+}$ and chromates $\mathrm{Cr}^{6+}$. ${ }^{2}$ In natural waters, $\mathrm{Cr}$ exists mainly in two different oxidation states, $\mathrm{Cr}^{6+}$ and $\mathrm{Cr}^{3+}$. Chromium (VI) and chromium (III) enter the body through inhalation, ingestion and dermal contact. The trivalent and hexavalent forms are believed to be the biologically active species; but, their health impacts are not identical. Chromium (VI) readily penetrates biological membranes while chromium (III) generally does not. $\mathrm{Cr}$ (VI) is considered to be toxic because of its adverse effects on the health. ${ }^{3}$ On the other hand, $\mathrm{Cr}$ (III) is virtually both less toxic than $\mathrm{Cr}(\mathrm{VI})$ and required nutrient for living organisms. ${ }^{4}$ The most commonly reported chronic effects of chromium (VI) exposure include contact dermatitis, skin ulcers, irritation and ulceration of the nasal mucosa and perforation of the nasal septum. Less common are reports of hepatic and renal damage and pulmonary effects (bronchitis, asthma, and bronchospasm). ${ }^{5}$ Therefore, it is important to remove Chromium (VI) from polluted wa- ters, especially those belonging to the electroplating industry. In the drinking water, chromium contaminations are probably due to the industrial using of them such as mining, leather tanning, dye, cement and electroplating applications. ${ }^{6}$ The removal of $\mathrm{Cr}(\mathrm{VI})$ from wastewater is important before disposal of industrial waste into the water reservoirs such as river and lake. ${ }^{7}$ For the removal of the $\mathrm{Cr}(\mathrm{VI})$ from drinking water sources, different techniques such as chemical precipitation, electrokinetic remediation, membrane separation, bioremediation photocatalysis and adsorption are used. ${ }^{8}$ Among these techniques, adsorption of $\mathrm{Cr}(\mathrm{VI})$ can be effective and versatile method for chromium removal particularly owing to the more economically viable, especially if low cost adsorbents are used. But in practice its advantages are largely related to the performance of the adsorbents. Compared to conventional adsorbents, nanomaterials have been counted as very promising candidates for high-performance adsorbents in the most adsorbents, due to their higher surfaceto-volume ratio. ${ }^{9}$ Up to now, some adsorbents, such as such as carbon nanospheres and/or nanotubes, graphene derivatives, metal oxide nanoparticles, and other nano adsorbents have been widely researched for $\mathrm{Cr}$ (VI) removal. ${ }^{9-12}$ Considering that oxyanions are the main form of 
chromate existing in water, the adsorption capacity of chromate can be expected to improve by introducing cationic units onto the adsorbent surface, because of the static electrical interaction between oxyanions and positive component on the adsorbent surface. ${ }^{13,14}$ Presence of the amino groups on the surface of adsorbents with various amino compounds is very effective route to prepare cationic adsorbents for the removing of the chromate ions. For instance, the chromate adsorption capacity of bare magnetic $\mathrm{Fe}_{3} \mathrm{O}_{4}$ nanoparticles from the aqueous phase was effectively improved after they were coated with piperidine units containing protonable amino groups at lower $\mathrm{pH}$ values. ${ }^{15,16}$ However, the large-scale treatment of magnetite nanoparticles in plants or water sources are still insufficient because of the challenges such asdemagnetization, large-scale synthesis and recycling process of magnetic nano adsorbent. Recently, nanofiber adsorbents have been attracting much attention due to the both high adsorption properties and packing and durability advantages of conventional fiber materials. ${ }^{17}$ From this point of view functionalized nano-fibers will be most important topic and used as affinity membranes for filtering heavy metals and toxic anions that are difficult to purify by conventional purification methods. Keeping the above aspects in view, we designed and synthesized a new kind of calixarene and polyacrylonitrile (PAN) nanofiber adsorbent for chromate removal via an electrospinning technique (Figure 1 and Figure 2). Furthermore, the extraction capacity of this newly developed nanomaterial for dichromate anions was also explored and studied at different $\mathrm{pH}$ values by solidphase extraction process. While PAN provides the flexibility, high surface area and porosity for good chromium adsorption, calixarene molecules containing protonable amino groups as piperidine on the surface of adsorbent sup-

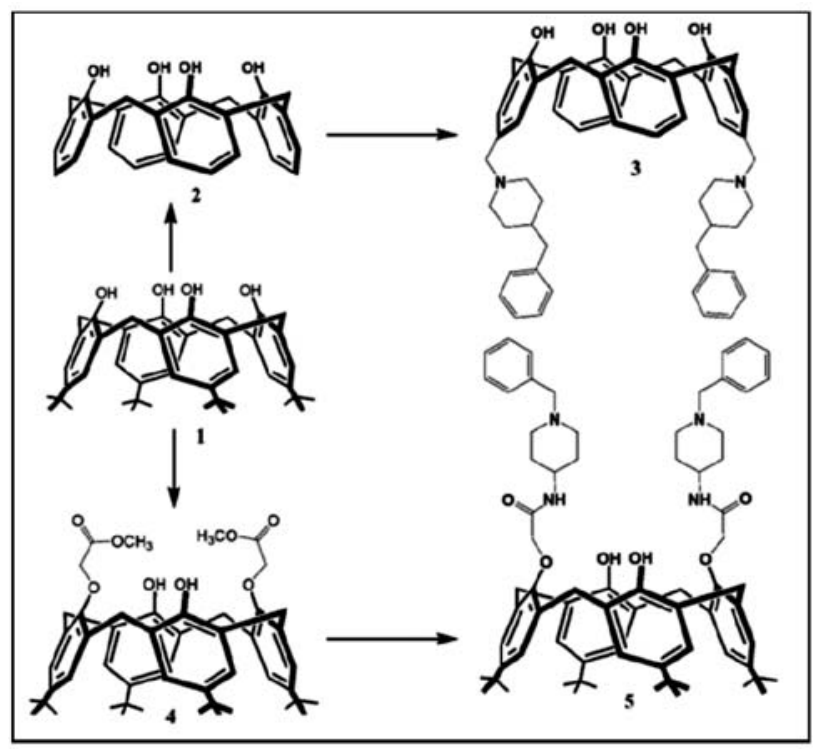

Figure 1. Synthetic route for the preparation of the lower rim or upper rim modified piperidine calixarene (3) and (5). port the possible interaction between surface and chromate anions with high affinity by electrostatic attraction.

\section{Experimental}

\section{1. General}

${ }^{1} \mathrm{H}$ and ${ }^{13} \mathrm{C}$ NMR spectra were obtained using a Varian $400 \mathrm{MHz}$ spectrometer operating at $400 \mathrm{MHz}$. The prepared nanofiber mats were characterized by using a Bruker Vertex 70 ATR-FTIR instrument. Thermogravimetric analysis (TGA) data were obtained with a Setaram SETSYS thermal analyzer. SEM images were received using a Zeiss LS-10 field emission SEM instrument. UV-Visible spectra were recorded on Shimadzu 1800 UV-Visible. Millipore Milli-Q Plus water purification system is used for the distilled water. For the $\mathrm{pH}$ measurements, An Orion 410Ap pH meter was used. All of the reagents used in this study were obtained from analytical grade and used without further purification.

\section{2. Synthesis}

p-tert-butylcalix[4]arene (1), calix[4]arene (2), 5,17-Bis-[(4-benzylpiperidine)methyl]-calix[4]arene (3), $p$-tert-butylcalix[4]arene diester (4) and p-tert-butylcalix[4]arene diamide (5) compounds were synthesized according to the literature procedures. ${ }^{15-18}$

\section{3. Electrospinning}

Fibers were electrospun as reported in literatures. ${ }^{17-20}$ The polymer solution were prepared by dissolving calixarene compounds in DMF which is containing $15 \%(w / v)$ PAN. The concentration of calixarenes was 50 wt\% with respect to the PAN concentration in DMF. The polymer solution was held in a horizontally plastic syringe fitted with a metallic needle of $0.7 \mathrm{~mm}$ inner diameter. A stainless steel electrode was immersed in the solution and connected to a high voltage power supply. A metal plate coated with aluminum foil placed opposite served as a counter electrode. The applied voltages between the needle tip and collector were set at around $15-20 \mathrm{kV}$ with a tip-to-collector distance of $15 \mathrm{~cm}$. The electrospinning temperature and the relative humidity were $25{ }^{\circ} \mathrm{C}$ and $50 \%$, respectively.

\section{4. Adsorption Experiments}

The sorption capacities of the prepared nanofibers were determined by the following technique. Aqueous solution $(10 \mathrm{~mL})$ of $\mathrm{Na}_{2} \mathrm{Cr}_{2} \mathrm{O}_{7}$ with $1.0 \times 10^{-4} \mathrm{M}$ concentration and $25 \mathrm{mg}$ of the sorbent were pipetted in a stoppered flask that was shaken at $175 \mathrm{rpm}$ and $25{ }^{\circ} \mathrm{C}$ for $1 \mathrm{~h}$. The sorbent was separated before measurements. The residual dichromate concentration of aqueous solute was determi- 
ned by UV-Vis analyses at $346 \mathrm{~nm}$. The effect of $\mathrm{pH}$ was studied by adjusting the $\mathrm{pH}$ of aqueous solutions using diluted $\mathrm{HCl}$ and $\mathrm{KOH}$ solutions at $25{ }^{\circ} \mathrm{C}$. The experiments were performed three times. From the blank experiments data it was observed that no dichromate extraction occurred in the absence of the fiber mats. The percent extraction (E \%) was calculated through the absorbance of the aqueous phase measured using the following expression:

$$
\text { Extraction } \mathrm{E} \%=\left(\mathrm{A}_{0}-\mathrm{A}\right) / \mathrm{A}_{0} \times 100
$$

where $\mathrm{A}_{0}$ and $\mathrm{A}$ are the initial and final concentrations of the dichromate ion before and afterthe extraction, respectively (Eq. 1).

\section{Results and Discussion}

\section{1. Synthesis and Characterization}

The synthesis of desired calix[4]arene derivatives containing piperidine units at upper rim or lower rim is depicted in the Figure 1. For this purpose, the required starting materials, $p$-tert-butylcalix[4]arene (1), calix[4]arene (2) and diester derivative (4) were synthesized by following the procedure available in the literature. ${ }^{18}$ In case, compounds (3) and (5) were prepared according to previous reports as follow. ${ }^{15,16}$ For the lower rim modified calixarene derivative, starting material (4) and 4-amino-1-benzylpiperidine were reacted in refluxing toluene-methanol solvent mixture. After 10 days, crude product was purified by column chromatography $\left(\mathrm{SiO}_{2}\right.$, EtOAc/n-hexan; 2:1) and lower rim modified calixarene based piperidine was obtained as a pale yello- wish solid with $54 \%$ yields. As for upper rim functionalized calixare derivative (3), calix[4] arene (2) were interacted with 4-benzylpiperidine in presence of formaldehyde and acetic acid in THF at room temperature and upper rim functionalized compound (3) was obtained as a white solid product with 53\% yields after 24 hours via Mannich type reaction. After synthesis of the calix[4]arene compounds containing piperidine units, polyacrylonitrile (PAN) nanofibers containing calixarene piperidine derivatives were electrospun from the dimethylformamide solution mixture of PAN and calixarene molecules (3) and (5). For the comparison study, pure PAN nanofibers without calixarene molecules were also electrospun.

Fracture morphologies of pure PAN, PAN-CLX3 and PAN-CLX4 nanofibers can be seen in Figure 3. The SEM images of nanofibers showed that there was no phase separation in the cross sectional morphology and they were comparable. In the case of PAN with and without calixarene units, while the nanofibers were mostly uniform, in the fiber matrix, aggregates of calixarene crystals were also distributed. Mostly, the fiber diameters were between 285 and $330 \mathrm{~nm}$ for all the samples. But, compared the samples, small variations were observed. For PAN-calixarene systems, slightly thicker fibers were obtained when compared to pure PAN system owing to the higher solution viscosity by the presence of calixarene molecules. In the case of pure PAN system, thinner fibers were observed because of the absence of calixarene molecules caused the lower viscosity of pure PAN in DMF solution. As clearly seen from SEM images, the surface morphologies of all PAN- CLX3 and PAN- CLX5 nanofibers were obviously different from the pure PAN nanofibers.

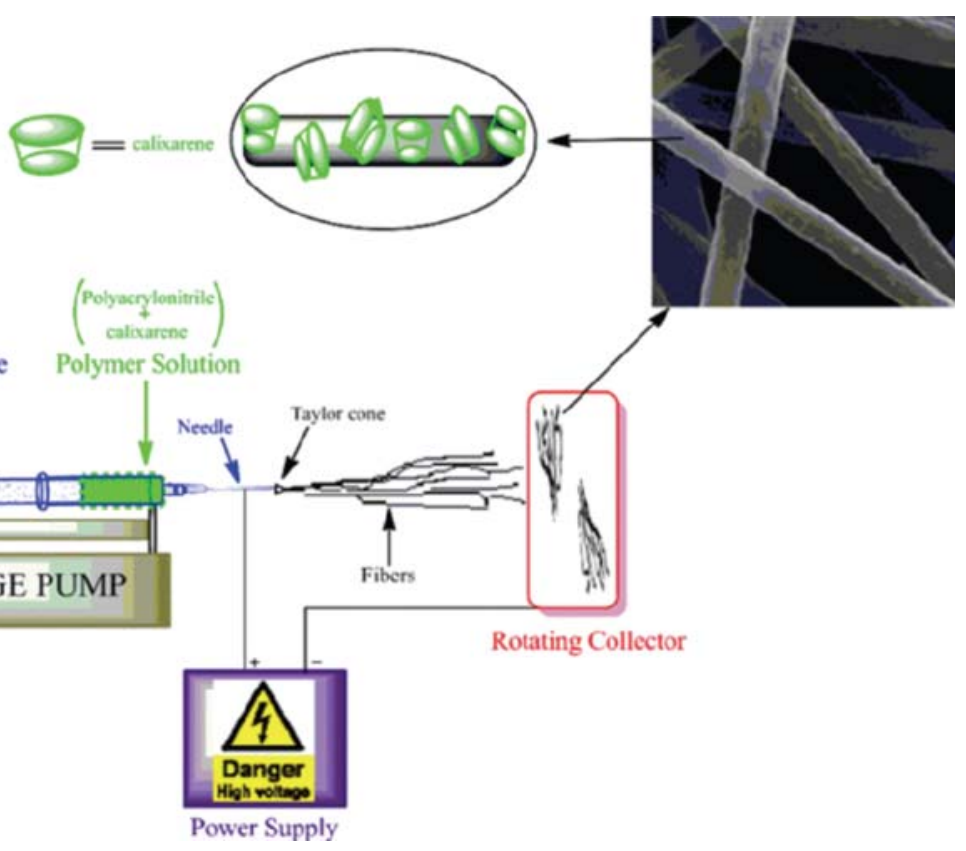

Figure 2. A setup for the electrospinning process of calixarene compounds (3),(5) and polyacrylonitrile solutions. 


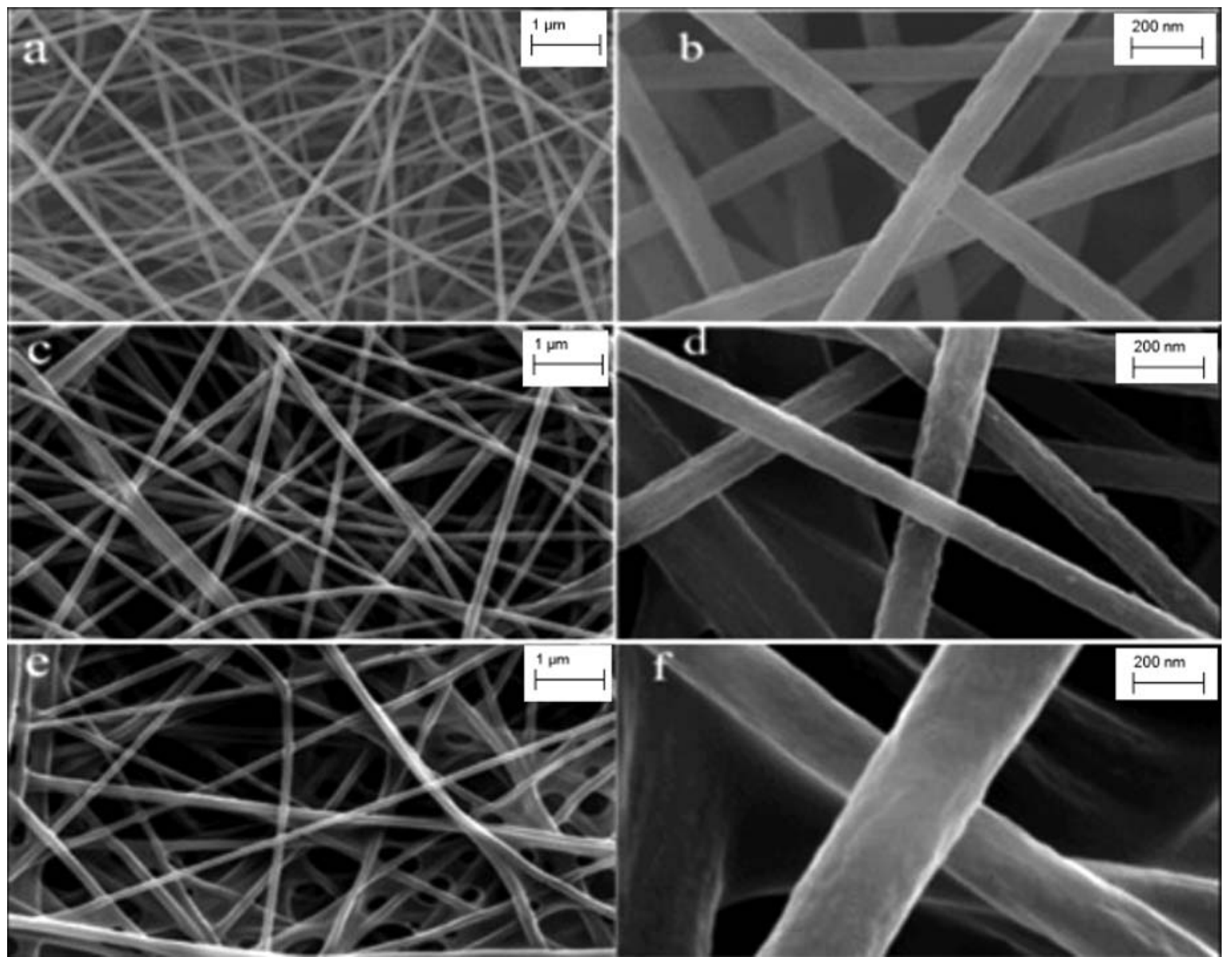

Figure 3. SEM images of prepared nanofibers: a. and b. pure PAN; c. and d. PAN-CLX5; e. and f. PAN-CLX3.

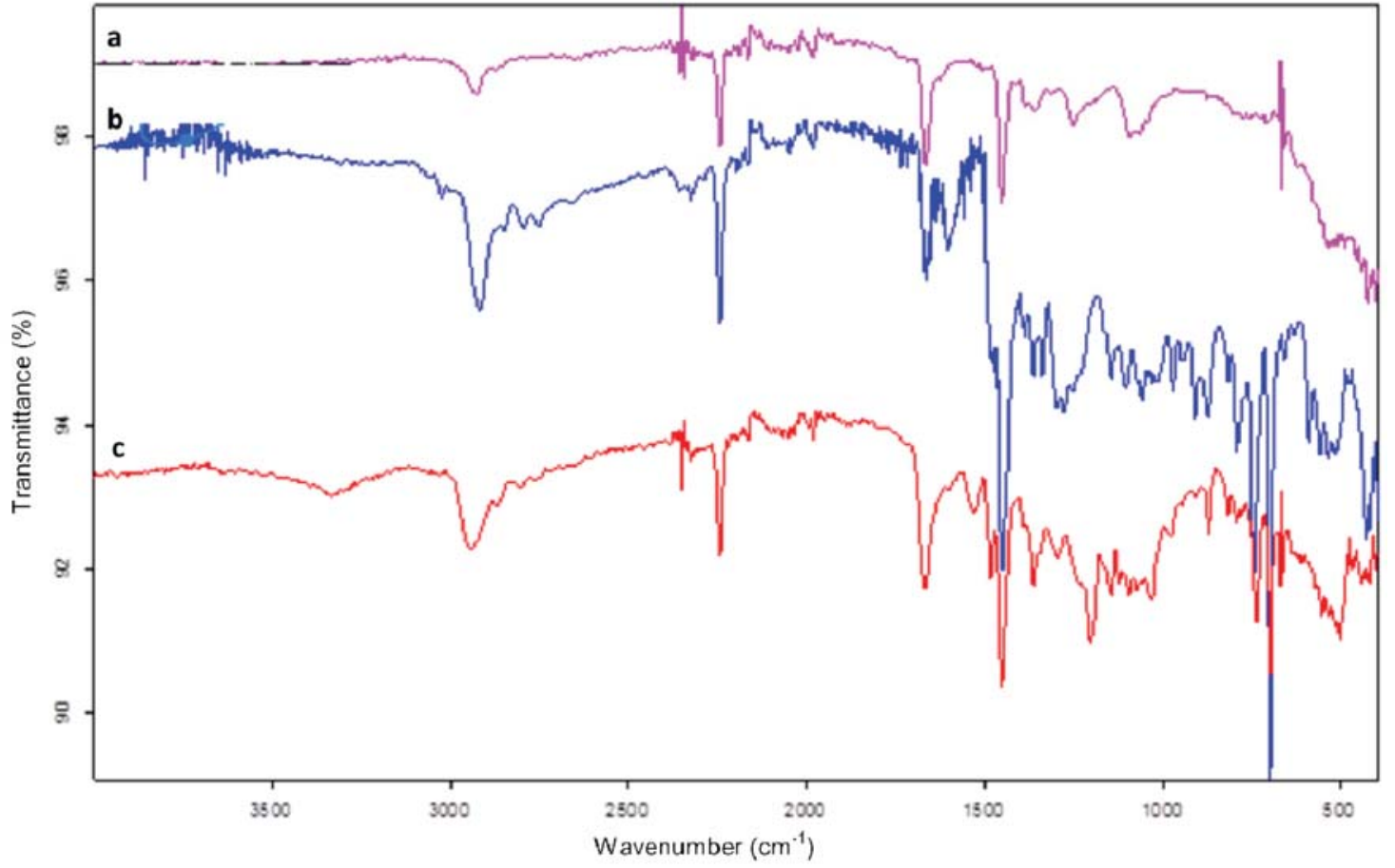

Figure 4. FTIR (ATR) spectra of prepared nanofibers. (a: pure PAN, and b: PAN-CLX3 and c: PAN-CLX5) 
To confirm the presence of calixarene molecules on the surface of fiber webs, PAN- CLX3, PAN- CLX5and pure PAN analyzed by a surface sensitive technique, attenuated total reflection Fourier transform infrared (ATRFTIR) spectroscopy. The ATR-FTIR spectra of (a) pure PAN, (b) PAN- CLX3 and (c) PAN- CLX5 nanofibers are presented in Figure 4. Typical bands include stretching vibrations of $\mathrm{CH}$ and $\mathrm{CH}_{2}$ groups at $2800-3000 \mathrm{~cm}^{-1}$, intense stretching vibration of $\mathrm{CN}$ at $2240 \mathrm{~cm}^{-1}$ and $\mathrm{CH} / \mathrm{CH}_{2}$ deformation vibrations at $1250-1500 \mathrm{~cm}^{-1}$ were observed in the all FTIR spectrum. ${ }^{19,20}$ On the other hand, the absorption bands at around 3462 and $1667 \mathrm{~cm}^{-1}$ attributable stretching vibration of phenolic hydroxyl groups and the phenyl plane bending vibration observed for PAN-CLX3 and PAN-CLX5 nanofibers were also observed, respectively. These new bands confirmed that calixarene molecules were present on the surface of the nanofibers. In addition, the absorption bands corresponding to stretching vibration of amide band I and amide band II for PANCLX3 nanofibers were observed at around 1650 and 1530 $\mathrm{cm}^{-1}$,respectively.Moreover, the frequency of the mentioned typical bands ascribed to the structure of calixarene skeleton was found to be unaffected by the electrospinning process. For this reason, no covalent bond formation between calixarene molecules and PAN was evidenced from the FTIR analysis. Therefore, incorporation of calixarene molecules containing piperidine units into nanofiber scaffold was evaluated as a process which is governed by strong physical interactions.

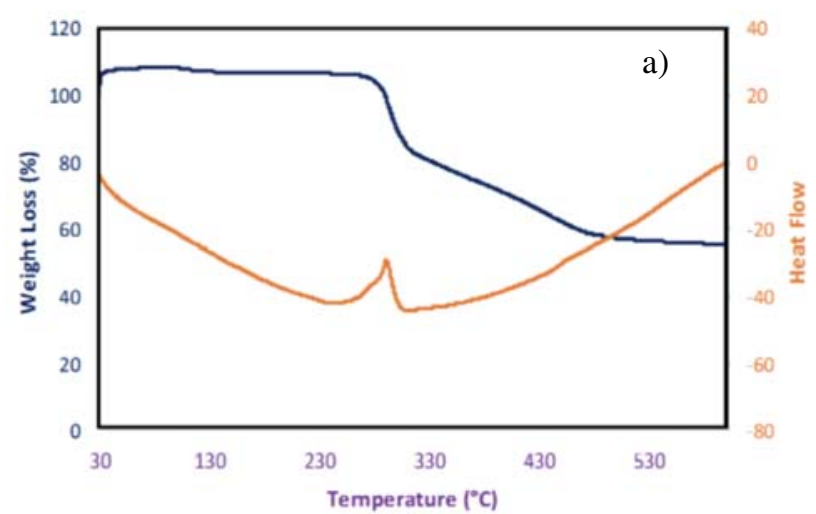

The thermal behaviors of the prepared nanofibers was determined by thermo gravimetric analysis in a temperature range of $25-600{ }^{\circ} \mathrm{C}$. TG curves of (a) PAN, (b) PAN-CLX3 and (c) PAN-CLX5 were presented Figure 5. The first and rapid weight loss of PAN nanofibers was observed between 275 and $330{ }^{\circ} \mathrm{C}$ due to the side chain degradation of the polymer backbone. Decomposition of the carbon-carbon main chains caused the weight loss was seen around $360-465{ }^{\circ} \mathrm{C}$ in TGA curves for all nanofibers. Compared with PAN nanofibers, it is clearly seen from the inset of Figure 5 that PAN-CLX3 and PAN-CLX5 nanofibers begin to lose weight at slightly shorter temperatures demonstrating a stabilizing effect of calixarene molecules into the polymer chain. The thermal decomposition behaviors of the PAN nanofibers with calixarene molecules are slightly higher than pure PAN. Furthermore, DSC curves displayed an exothermic for all samples and endothermic peaks only for calix nanofibers, which indicated thermal stabilizing, cyclization of nitrile group and melting process of PAN nanofibers. The exothermic peak of pure PAN displayed at $290{ }^{\circ} \mathrm{C}$ due to multiple complex chemical reactions, such as dehydrogenation, instantaneous cyclization and crosslinking reactions associated with the oxidative stabilization of PAN. ${ }^{21,22}$ In addition, the weak endothermic peaks attributable the melting of the pure calixarene compounds for PAN-CLX3 and PAN-5 during the heating stage, which are centered around 200 ${ }^{\circ} \mathrm{C}$, were also observed.

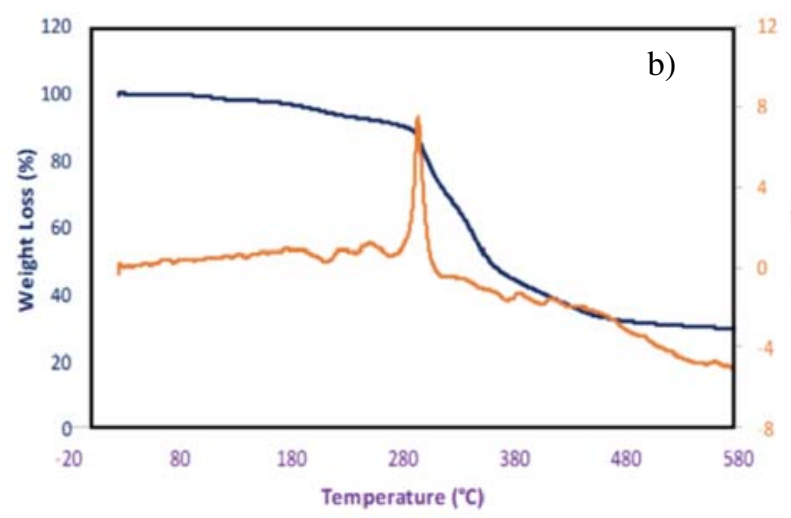

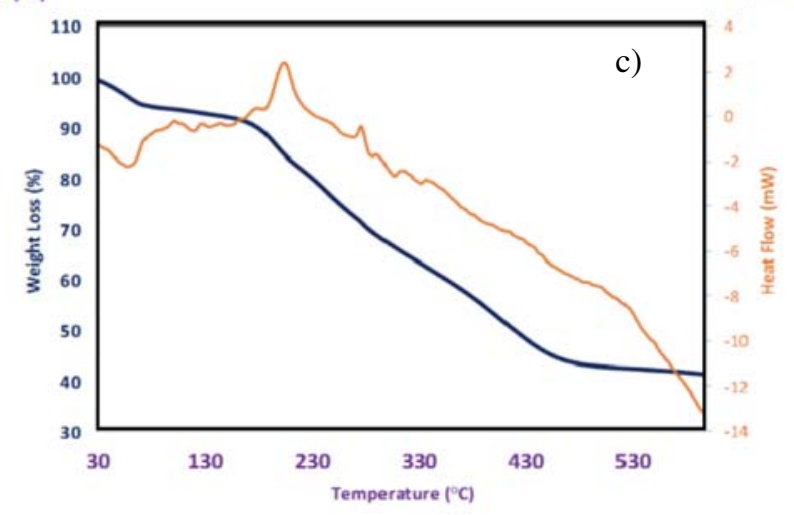

Figure 5. TG and DSC curves of nanofibers (a) PAN, (b) PAN-CLX3 and (c) PAN-CLX5. 


\section{2. Chromate Extraction Studies}

From the spectroscopic data, it can be seen that the obtained fibers are porous and amine modified calixarene molecules were immobilized on the surface. This distinct morphology of the resultant nanofiber mats would be very favorable to the adsorption of anionic chromate ions. The synthesis of supports and hosts for specific anions as dichromate is an important goal. Because $\mathrm{Cr}$ (VI) has well known effects on environment and living organism, it is necessarily to remove $\mathrm{Cr}(\mathrm{VI})$ from wastewater. Therefore, a series of experiments were carried out to evaluate the binding capability of nanofibers mats towards chromate ions in aqueous solution. The effect of $\mathrm{pH}$ on the chromate adsorption abilities of the prepared nanofibers pure PAN, PAN-CLX3 and PAN-CLX5 at room temperature was presented at Figure 6. From the adsorption experiments, It was found that the chromate uptake ability of the nanofibers PAN-CLX3 and PAN-CLX5 reached a maximum at $\mathrm{pH}$ 1.5. When the $\mathrm{pH}$ of studied solutions gradually decreased, the adsorption performance for PAN-CLX3 and PAN-CLX5 sharply increased. From Figure 6, it is clear that maximum extraction $90 \%$ for PAN-CLX3 and $85 \%$ for PAN-CLX5 occur in aqueous solution at $\mathrm{pH} 1.5$; which shows that best interaction between fibers PAN-CLX3, PAN-CLX5 and the chromate ions occurs at this $\mathrm{pH}$. On the other hand, pure PAN nanofibers have almost no adsorption capacity for chromate anions, whereas calixarenemodified nanofiber exhibited increased adsorption percentage at different $\mathrm{pH}$ values. The following reasons should be accountable for these findings. Firstly, the amino groups of calixarene piperidine molecules on the surface of fiber mats are prone to protonation in acid solution which enhances the electrostatic interaction between protonated calix piperidine units and anionic chromate ions as well hydrogen bonding. The next reason is that PAN nanofibers based calixarene containing piperidine units have a more stable skeleton and functionalized groups due to presence of calixarene molecules. With increasing $\mathrm{pH}$ values, the possible interaction between chromate ions and fiber webs at aqueous solutions decreased and the extraction percentage became less for all studied nanofibers. The slight increase in anion binding efficiency of all nanofibers at increased $\mathrm{pH}$ values (from 5.5 to 8.5 ) may be explained by the location of the sodium cation coming from dichromate so-called ion-pairs. $\mathrm{Cr}$ (VI) is unstable and shows very oxidizing behaviors in the presence of the electron donor in acidic medium. $\mathrm{HCrO}_{4}^{-}$is the dominant form of the chromium at $\mathrm{pH} 1$ and 6 and only $\mathrm{CrO}_{4}^{-2}$ ions exist above $\mathrm{pH} 7$. With the increase of $\mathrm{pH}$, the proportion of $\mathrm{HCrO}_{4}^{-}$decreased and the content of $\mathrm{CrO}_{4}^{2-}$ increased until it was the predominant species at $\mathrm{pH}$ values over 7.5.

Apparently, the $\mathrm{CrO}_{4}{ }^{2-}$ oxyanion needs one more adsorption site than the $\mathrm{HCrO}^{-}$oxyanion. It is understandable that the adsorption capacity decreased with the $\mathrm{pH}$ increasing from 1.5 to 8.5. Compared the published literature results about dichromate extraction by solid materials as magnetite nanoparticle with piperidine units, fiber version of calixarene piperidine molecules showed excellent extraction results. ${ }^{15,16}$ These results are probably due to the special and large surface area, high porosity, microporesity and high flexibility properties of the fiber structures of calixarene piperidine nanofiber mats. At the lower $\mathrm{pH}$ values both the formation of $\mathrm{HCr}_{2} \mathrm{O}_{7}^{-} \mathrm{Na}^{+}$and the protonation of the amine nitrogens of piperidine units of calixarene molecules favor extraction. Additionally, both the competing ion and temperature effect on chromate anion extraction of PAN-CLX3 and PAN-CLX4 was explored by using the mixture of $\mathrm{Cl}^{-}, \mathrm{SO}_{4}{ }^{2-}, \mathrm{NO}_{3}{ }^{-}$and chromate anions at the different temperatures such as 25,30 and 35 ${ }^{\circ} \mathrm{C}$. From the obtained results, it was clearly observed that both the presence of the competing ions such as $\mathrm{Cl}^{-}$, $\mathrm{SO}_{4}{ }^{2-}, \mathrm{NO}_{3}{ }^{-}$and different temperature values did not have any considerably effect onto the extraction percentage of chromate ions with PAN-CLX3 and PAN-CLX4. In the light of these results, PAN-CLX3 and PAN-CLX4 nanofibers could be used as selective ionophore based nanofibers for chromate anions in the presence of foreign anions at different temperatures.
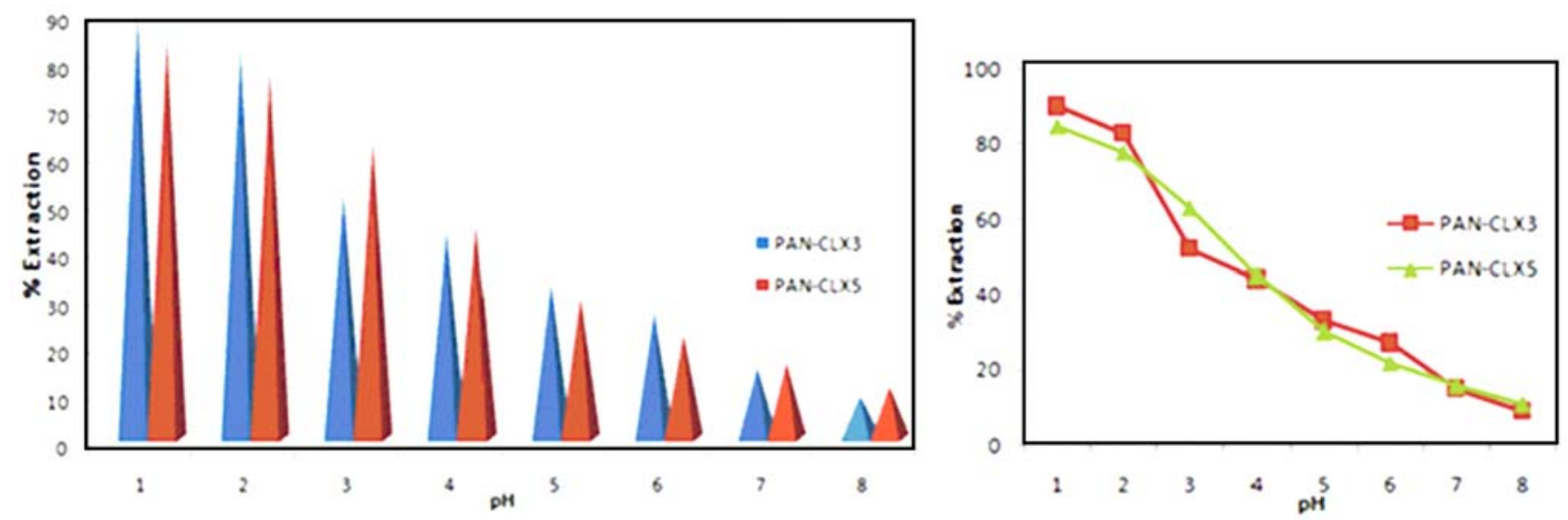

Figure 6. Extraction percentages (\%E) versus pH following the solid phase extraction of dichromate anions with nanofibers PAN-CLX3 and PANCLX5. 


\section{Conclusion}

As a summary in this study, the preparation and anion binding properties of PAN nanofibers based calixarene containing piperidine units with amide and/or amine functionality were successfully carried out. In the fabrication process, PAN nanofibers based calixarene piperidine units were first produced with the aim to develop functional nanofibers. Owing to the presence of calixarene piperidine molecules onto the nanofiber scaffold, PAN-CLX3 and PAN-CLX5 exhibited higher affinity toward chromate anions. This situation is probably due to the very high surface area, porosity, flexibility and microporesity of PAN nanofibers and surface associated with calixarene molecules. Calixarenes are already being used in variety areas such as pharmaceuticals, catalyst, filtrations and controlled drug delivery systems, therefore, having nanofiber structures might hopefully extend the use of calixarenes in these fields or in other functional systems. Hence, a new inexpensive material is proposed via electrospinning as a useful membrane type adsorbent for removal of chromate anions in aqueous solution. Moreover, our findings may contribute to the fabrication of new functional nanofibers from other types of calixarene and/or other supramolecular systems via electrospinning.

\section{Acknowledgments}

The authors gratefully would like to thank Karamanoglu Mehmetbey University Research Foundation (Project number 25-M-15) for financial support.

\section{References}

1. A. E. P. Del Real, J. M.Silvan, S. de Pascual-Teresa, A. Guerrero, P. García-Gonzalo, M. C. Lobo, A. Pérez-Sanz, Environ. Sci. and Pol. Res. 2017, 1-11. https://doi.org/10.1007/s11356-016-8218-4

2. J. S. Chin, A. I. Gopalan, N. Muthuchamy, K. P. Lee, Polymers 2016, 8, 445.

https://doi.org/10.3390/polym8120445

3. L. C. Hsu, S. L.Wang, Y. C. Lin, M. K.Wang, P. N. Chiang, J. C.Liu,Y. M. Tzou, Enviro. sci.\& tech. 2010, 44, 6202-6208. https://doi.org/10.1021/es1017015

4. M. Gheju, Water. Air Soil Pol. 2011, 222, 103-148. https://doi.org/10.1007/s11270-011-0812-y
5. T. Burks, PhD Thesis. KTH Royal Institute of Technology 2016.

6. D. K. Harijan, V. Chandra, J. Environ. Chem. Eng. 2016, 3006-3012. https://doi.org/10.1016/j.jece.2016.06.014

7. R. Bhateria, D. Jain, Sustain Water Resour. Manag. 2016, 2 , 161-173. https://doi.org/10.1007/s40899-015-0014-7

8. S. Kuppusamy, T. Palanisami, M. Megharaj, K. Venkateswarlu, R. Naidu, I Rev. Environ. Contam. and Toxic. 2016, 236, 117-192. https://doi.org/10.1039/C5RA26973C

9. Y. Ma, B. Zhang, H. Ma, M. Yu, L. Li, J. Li, $R S C A d v$. 2016, 6, 30739-30746. https://doi.org/10.1007/978-3-319-20013-2

10. M. Li, C. Wang, M. J. O'Connell, C. K. Chan, Environ. Science: Nano 2015, 2, 245-250. https://doi.org/10.1039/C4EN00204K

11. L. Yu, Y. Ma, C. N. Ong, J. Xie, Y. Liu, Rsc. Adv. 2015, 5, 80, 64983-64990. https://doi.org/10.1039/C5RA08922K

12. L. Zhang, W. Xia, X. Liu, W. Zhang, J. Mater. Chem. A 2015, 3, 331-340. https://doi.org/10.1039/C4TA05194G

13. A. Benhamou, J. P. Basly, M. Baudu, Z. Derriche, R. Hamacha, J. Colloid Interface Sci. 2013, 404, 135-139. https://doi.org/10.1016/j.jcis.2013.04.026

14. T. Wang, L. Zhang, C. Li, W. Yang, T. Song, C. Tang, J. Luo, Environ. Sci. Tech. 2015, 49, 5654-5662. https://doi.org/10.1021/es5061275

15. S. Sayin, M. Yilmaz, M. Tavasli, Tetrahedron 2011, 67, 3743-3753. https://doi.org/10.1016/j.tet.2011.03.012

16. S. Sayin, F. Ozcan, M. Yilmaz, A. Tor, S. Memon, Y. Cengeloglu, CLEAN-Soil. Air. Wat. 2010, 38, 639-648. https://doi.org/10.1002/clen.201000039

17. F. Ozcan, M. Bayrakcı, S. Ertul, J. Incl Phenom. Macrocycl. Chem. 2016, 85, 49-58. https://doi.org/10.1007/s10847-016-0604-5

18. C. D. Gutsche, K. C. Nam, J. Am. Chem. Soc. 1988, 110, 6153-6162. https://doi.org/10.1021/ja00226a034

19. Y. Liu, G. Jiang, L. Li, H. Chen, Q. Huang, T. Jiang, X. Du, W. Chen, J. Mater. Sci. 2015, 50, 8120-8127. https://doi.org/10.1007/s10853-015-9385-2

20. H. Chen, G. Jiang, W. Yu, D. Liu, Y. Liu, L. Li, Q. Huang, Z. Tong, W. Chen, Powder Technol. 2016, 298, 1-8. https://doi.org/10.1016/j.powtec.2016.05.017

21. L. Ji, Z. Lin, M. Alcoutlabi, O. Toprakci, Y. Yao, G. Xu, X. Zhang, Rsc. Adv. 2012, 2, 192-198. https://doi.org/10.1039/C1RA00676B

22. M. Bayrakc1, F. Ozcan, S. Ertul, Tetrahedron 2015, 71, 3404-3410. https://doi.org/10.1016/j.tet.2015.03.090

\section{Povzetek}

Molekule kaliksarena s piperidinskimi enotami v zgornjem ali spodnjem obroču skeleta smo uporabili za pripravo vodoodpornega komposita nanovlaken. V procesu electropredenja smo uporabili polimeren nosilec poliakrilnitril (PAN). Tako pripravljen adsorbent na osnovi PAN kaliksaren nanovlaken je pokazal odlično adsorpcijsko kapaciteto napram toksičnim anionom kroma (VI) v vodnih raztopinah. Nova nanovlakna predstavljajo obetajoč material za pripravo filtrov za čiščenje pitne vode. 